\title{
How Ebola and Marburg viruses battle the immune system
}

\section{Mansour Mohamadzadeh*‡, Lieping Chen ${ }^{\ddagger}$, and Alan L. Schmaljohn*}

Abstract | The filoviruses Ebola and Marburg have emerged in the past decade from relative obscurity to serve now as archetypes for some of the more intriguing and daunting challenges posed by such agents. Public imagination is captured by deadly outbreaks of these viruses and reinforced by the specter of bioterrorism. As research on these agents has accelerated, it has been found increasingly that filoviruses use a combination of familiar and apparently new ways to baffle and battle the immune system. Filoviruses have provided thereby a new lens through which to examine the immune system itself.
Pantropic

Tending towards the capacity to infect a wide range of cells and organs.

\section{Coagulopathy}

Refers to a group of conditions of the blood-clotting system in which bleeding is prolonged

and excessive.

Cell tropism A virus's affinity for or tendency towards preferential infection of certain cells.
*US Army Medical Research Institute for Infectious Diseases, Frederick, Maryland, USA;

‡Johns Hopkins University School of Medicine

Baltimore, Maryland, USA. Correspondence to M.M. and A.L.S. e-mails:

Mansour.mohamadzadeh @amedd.army.mil;

Alan.Schmaljohn @amedd.army.mil doi:10.1038/nri2098
The known animal viruses are remarkably diverse in the ways in which they sustain themselves in nature, occasionally wreaking havoc in their preferred or accidental hosts. The immune system is central in this battle for survival, which is exemplified here by the cases of Ebola and Marburg virus (EBOV and MARV, respectively) infections in primates. In healthy but unvaccinated monkeys or humans infected with the most virulent strains of EBOV and MARV, the immune system loses the battle in nearly $90 \%$ of encounters, not slowly and inexorably as with some viruses, but in a matter of days (BOX 1). The reasons seem to reside in a complex series of interrelated viral and immune events.

As will be discussed, it seems that EBOV and MARV relentlessly infect cells of the monocyte-macrophage lineage, accelerating the release of pro-inflammatory cytokines, including tumour-necrosis factor (TNF) and interferon- $\gamma$ (IFN $\gamma$ ), which in turn can disrupt the architecture of the vascular endothelium ${ }^{1,2}$ and other tissues (BOX 1; FIG. 1). The triggering of neutrophils and perhaps other polymorphonuclear leukocytes by interactions between viral particles and triggering receptors expressed on myeloid cells (TREMs) or Toll-like receptors (TLRs) provides another source of the copious amounts of inflammatory mediators produced as the viral burden increases during the course of infection. Along with fever, diarrhoea is a frequent symptom, and both dehydration and septicaemia become risks. Overshadowing everything is the inexorable replication of the virus, beginning in dendritic cells (DCs), monocytes and various types of macrophage, but proceeding to a more pantropic profile in which only certain cells - notably lymphocytes - are spared. In the case of MARV, hepatocytes are particularly susceptible, elevated liver enzymes are among the first telling signs of disease and liver damage seems to account for much of the coagulopathy ${ }^{3,4}$. Coincident with and underlying the unchecked viral replication, filoviruses deceive and dysregulate both innate and adaptive immune responses. Here, we describe recent findings pertinent to the clash between virus and host defences, summarize and briefly highlight the progress in the development of filovirus vaccines and therapeutics (BOX 2) and attempt to illuminate crucial areas in which questions and opportunities remain.

First encounters: receptor-mediated tropisms

The observed distribution of filoviruses in animals in the first days of infection ${ }^{5-7}$, as well as various in vitro experiments, show that DCs, monocytes and macrophages are early targets of infection. This distribution occurs in a larger context in which filoviruses show diverse cell tropism and can eventually be found in numerous non-lymphocytic cell types in later stages of disease $\mathrm{e}^{7,8}$.

There seem to be several cellular receptors for filoviruses, and to the extent that they have been identified, they appear to be relatively nonspecific or pattern based (FIG. 2). Therefore, C-type lectins, such as DC-specific intercellular adhesion molecule 3 (ICAM3)-grabbing non-integrin (DC-SIGN; also known as CD209) or liver/ lymph node-SIGN (L-SIGN; also known as CLEC4M), are sufficient to confer permissive filovirus glycoproteinmediated infection ${ }^{9}$. Moreover, human macrophage C-type lectin specific for galactose $/ \mathrm{N}$-acetylgalactosamine (hMGL) that is expressed by cells of monocytic origin (such as immature DCs) also promotes filoviral entry $^{10}$. Another C-type lectin, the asialoglycoprotein 
Plasmacytoid dendritic cells (pDCs). A distinct subset of DCs that differ from conventional myeloid DCs in their capacity to produce copious amounts of interferon- $\gamma$ in response to many viruses and Toll-likereceptor ligands.

Invariant natural killer T cell (iNKT cell). A cell type thought to be particularly important in bridging between innate and adaptive immunity. iNKT cells are typified by a capacity for self-recognition and rapid release of cytokines such as interferon- $\gamma$. receptor that is expressed by hepatocytes, has specific affinity for the $\mathrm{N}$-linked sugar chains with terminal galactose residues of MARV glycoproteins ${ }^{11}$ and therefore initiates filoviral cell infectivity by facilitating viral cell entry. Conversely, the binding of filoviruses to C-type lectin molecules is significantly inhibited by the carbohydrate mannan, which indicates that the binding is due to the interaction between carbohydrate motifs on the surface of host cells and N-linked carbohydrate structures of glycoprotein on the filoviral surface. Recently, we also observed that a class of immunorecognition receptors known as TREMs, which are implicated in the amplification of septic shock and cell activation, might have a crucial early role in the interaction of filoviruses with neutrophils ${ }^{12}$, monocytes and mature DCs.

Collectively, these observations about the binding of filoviruses to the C-type lectin and TREM receptors on cells of myeloid lineage are consistent with in vivo observations. Nevertheless, as filoviruses are pantropic and other infected cell types, such as endothelial and epithelial cells, do not express C-type lectins or TREMs, there might be other ubiquitous molecules, such as heparin-sulphate proteoglycan (HSPG; also known as SDC2 $)^{13}$ and folate receptor- $\alpha$ (REF. 14), involved in viral- and host-receptor-mediated entry.

If this complexity were not enough, it has been shown that filoviral glycoproteins are glycosylated differently, depending on the cells in which they are grown ${ }^{15}$, and that they bud from lipid rafts ${ }^{16}$ (a process in which viral particles might passively acquire host proteins that influence viral cell tropism). Further compounding the specificities of early interactions between viruses and cells, we recently observed that lactoferrin - an antimicrobial and immunoregulatory protein product that is released rapidly from preformed granules after

\section{Box 1 | Filovirus-disease basics}

The filamentous single-stranded negative-sense RNA viruses belonging the family now called Filoviridae were first recognized only in 1967 (Marburg virus (MARV)) and 1976 (Zaïre ebolavirus (ZEBOV) and Sudan ebolavirus (SEBOV)). Studies of ZEBOV have identified bats as potentially being among the natural hosts for ebolaviruses ${ }^{87}$, and epidemiological evidence for MARV is also consistent with bats being the wildlife reservoirs of these viruses. The impact of these viruses on individual bats and bat populations is relatively unknown, but the consequences of filoviral infections in humans and non-human primates can be devastating: an acute disease with human mortality rates as high as $89 \%$ for sizeable outbreaks of either ZEBOV ${ }^{88}$ or MARV ${ }^{89}$. The viruses are apparently even more deadly in non-human primates than humans, with mortality rates approaching $100 \%$ in most non-human primate species, including the ebolavirus species for which human disease is rare (Ivory Coast ebolavirus) or has not been observed at all (Reston ebolavirus) ${ }^{90}$.

In humans and monkeys, the hallmark of filoviral disease is unchecked viral growth that coincides with a relatively wide range of possible disease manifestations including fever, malaise, diarrhoea and vomiting, severe liver damage and various coagulation deficits that cause filoviruses to be categorized among the viral haemorrhagic fevers. The worst of the symptoms, including haemorrhage in a few individuals ${ }^{3,91}$, seem to flow from a 'cytokine storm', a profuse release of pro-inflammatory cytokines ${ }^{52}$ (FIG. 1). In addition to cytokine effects on vascular permeability, causes of excessive bleeding can include plummets in platelet numbers, severe liver damage and the activation of tissue factor in monocytes and macrophages ${ }^{92}$. The time from infection to death is generally 1-2 weeks, with some variability depending on the virus and host species, as well as on initial dose ${ }^{93}$. For survivors, recovery is a lengthy process. the binding of filoviruses to neutrophils - can act to enhance the uptake of filoviruses by immature $\mathrm{DCs}^{17}$. This observation was in direct contrast to a previous report in which lactoferrin inhibited the transmission of HIV in vitro ${ }^{18}$, but illustrates a larger principle: soluble products that accompany infection and inflammation in vivo might affect viral cell tropisms in ways that could be either helpful or damaging to the host.

Other molecules to consider in the engagement of MARV and EBOV with neutrophils and monocytes are TLRs, which are often central in the ability of innate immune cells to detect various pathogenic agents and to establish adaptive immune responses. So far, our preliminary data indicate that the expression of TLR1, the signalling of which converges with that of TLR2, was significantly increased on EBOV- and MARV-activated neutrophils, whereas the expression of other TLRs was not modulated ${ }^{17}$. Further studies are required to establish the pathogenic importance and the accessibility to intervention of these many early interactions between filoviruses and innate immune cells.

\section{Dysregulation of initial innate immune activation}

For the initiation of an effective antiviral immune response, early events are crucial in establishing an appropriate balance of stimulatory and inhibitory signals that act in conjunction with antigen recognition. Early innate immunity may be conceived in two general forms: first, as a relatively unspecific response involving pattern-recognition molecules, pro-inflammatory cytokines and cell-based antiviral functions; and second, as an orchestrated preparation for an antigenspecific response involving $\mathrm{T}$ cells and antibodies. In this early balance, filoviruses cause several significant perturbations (FIGS 1-3).

Recently, filoviruses were found to be capable of disabling at least some of the host IFN pathway: the filoviral protein VP35 prevents the production of type I IFNs (that is, IFN $\alpha$ and IFN $\beta)^{19,20}$ and VP24 interferes with the ability of IFN $\alpha$, IFN $\beta$ and IFN $\gamma$ to induce an antiviral state in cells ${ }^{21}$ (FIG. 2). Furthermore, because IFNs are crucial factors that are secreted abundantly by DCs of the monocytic lineage and plasmacytoid DCs (pDCs), and which are responsible for the efficient activation of natural killer (NK) cells, invariant NKT cells ( $i$ NKT cells) and $\mathrm{T}$ cells ${ }^{22}$, the effects of IFN antagonism are implicated not only in the high viral burdens late in the course of disease, but also in much of the early dysregulation of innate immunity. Another factor that suggests additional complexities of IFN gene regulation in response to viral infection is that the overall IFN response is not ablated in vivo - elevated levels of IFN are frequently noted in the blood during acute infection.

For T-cell responses, and therefore also for T-celldependent antibody responses, DCs are pivotal as antigen-presenting cells (APCs) - in addition to presenting peptide antigen on MHC molecules, DCs can provide either co-stimulatory or co-inhibitory signals through various ligands. The first indications of filovirusmediated dysfunctions of DCs were typified by a generalized failure of EBOV- or MARV-infected human 


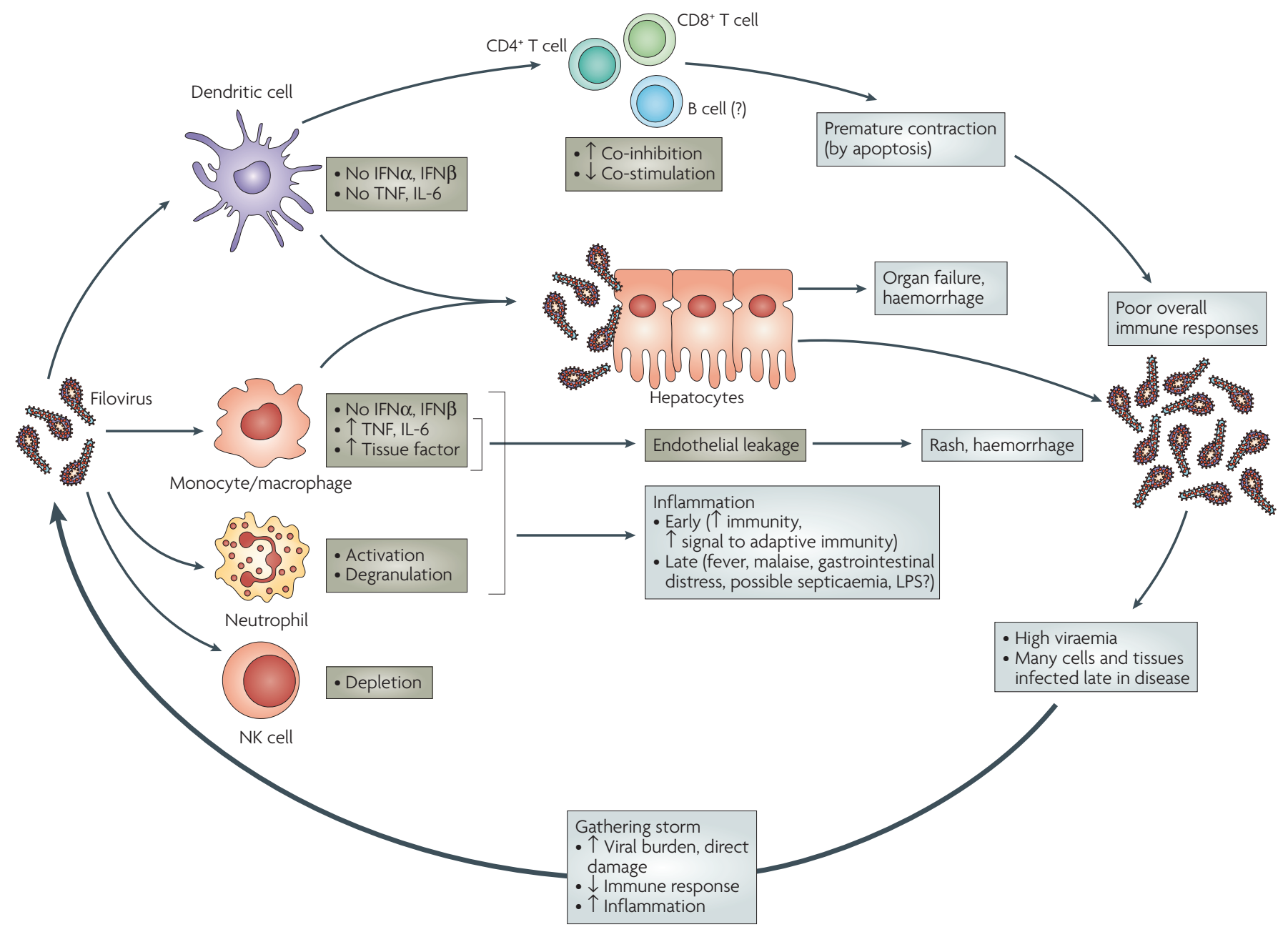

Figure 1 | System overview of filoviral pathogenesis. Initially, productive infection (that is, that which results in more viral progeny) occurs primarily in dendritic cells (DCs), monocytes and macrophages. All infected cells can be at least partially impaired in interferon (IFN) production, but some important differences have been described between DCs and monocytes: monocytes respond with the production of pro-inflammatory cytokines, whereas DCs conspicuously lack such a response. Neutrophils are not productively infected, nor are lymphocytes, but neutrophils are activated by interaction with viral particles with resultant degranulation and shedding of triggering receptor expressed on myeloid cells 1 (TREM1). As viral burden increases, lymphocyte apoptosis and a generalized failure of specific immune responsiveness are observed; we propose these to be rooted in virally induced upregulation of co-inhibitory molecules (such as B7-H1) on DCs and monocytes, followed by interaction with programmed death 1 (PD1) receptors on T and B cells. Infection spreads to many cells including liver hepatocytes, and the increasing release of pro-inflammatory cytokines crosses a threshold from beneficial to potentially harmful inflammation, also degrading vascular epithelium. As repeated cycles of viral replication overwhelm and outpace a dysregulated adaptive immune response, elements of innate immunity and inflammation that are potentially helpful early in the response only add to the spiralled dysfunction as they collide with high viral burdens. Dysfunctions in DCs, monocytes and macrophages are particularly important for their secondary effects on innate and adaptive immune responses, inflammation and vascular integrity.

DCs to make the transition from the immature to the mature antigen-presenting DC stage, and a concomitant failure to produce an array of pro-inflammatory cytokines required for T-cell signalling ${ }^{20,23}$. This selective loss of DC capabilities contrasted with earlier reports showing that monocytes and macrophages, like DCs, were susceptible to productive virus infection and were rendered incapable of IFN production, but, unlike DCs, responded by producing TNF and other proinflammatory cytokines ${ }^{1,24,25}$. Therefore, a virus-induced deficit in the co-stimulatory properties of infected DCs was implied, and was supported by the observation of a diminished capacity of such DCs to stimulate allogeneic T cells ${ }^{20}$.

Interestingly, NK cells, which are an effective early defence against filoviruses in mice ${ }^{26}$, might be among the host cells that are indirectly affected by the overall diminished synthesis of IFNs. Pre-treatment of animals with IFNs or IFN inducers before EBOV infection is considerably more effective in mice than in nonhuman primates ${ }^{27}$; this indicates a decisive difference in the susceptibilities of different species to the effects 


\section{Box 2 | Therapies for filovirus infection}

In simplest terms, therapeutic strategies are intended to slow the viral infection, treat symptoms and rely on immune clearance. Therefore, the clash between filoviruses and immune systems is expected to remain important even if effective therapies are developed. Currently, no effective therapies are available for human use, not even treatments useful shortly after exposure (and before disease symptoms develop), nor prophylactic measures. However, prospects for such therapies are encouraging, based on various preliminary successes in animal models (reviewed in detail elsewhere ${ }^{17,66,77,93}$ ). In brief, these include the possibility of therapy with virus-specific antibodies; mitigation of virus-induced coagulation deficits using recombinant nematode anticoagulant protein c2; antisense compounds or small interfering RNAs to inhibit viral genes; inhibitors of putative specific or nonspecific viral receptors on susceptible cells; interferons; and the possibility of using specific peptides to mitigate adverse consequences of interactions between filoviruses and neutrophils. Other potential vulnerabilities of the viruses, such as the viral fusion domain, cellular pathways required for viral exit or proteolytic cascades required for entry, are also open to therapeutic exploitation; even post-exposure vaccination shows promise.

of IFN antagonism that results from filoviral infection. Moreover, the effects of VP35, VP24 and perhaps other filoviral proteins might prove even more pleiotropic - not only IFN-related genes but also multiple cellular genes were perturbed by filoviral infection of hepatocytes, many of these genes were differently dysregulated depending on the filovirus species ${ }^{28}$. Further, it was shown previously that interleukin-8 (IL-8; also known as CXC-chemokine ligand 8 (CXCL8)), an $\alpha$-chemokine produced abundantly during filoviral infection, antagonizes the antiviral activity of IFN $\alpha$ by inhibiting the function of 2',5'-oligoadenylate synthetase (OAS) in encephalomyocarditis virus (EMCV) infection ${ }^{29}$. Accordingly, it may be worthwhile to explore the role of IL-8 in filoviral infections.

Further contributing to the initial immune response, viral replication in monocytes and macrophages continues unabated, enabled by the filoviral IFN-antagonist proteins and accompanied by the secretion of other non-inhibited pro-inflammatory cytokines. Viral particles, in turn, are able to trigger polymorphonuclear leukocytes (such as neutrophils) to expel the contents of their preformed granules and enter a state of activation ${ }^{12}$. Such early inflammatory responses are not extraordinary and might even be helpful in shaping normal immune responses ${ }^{30}$, but might also exacerbate an underlying early immune response dysfunction that originates principally in DCs.

Also potentially important are the roles of various cellular proteases (for example, cathepsins, furins and sheddases) (FIG. 2). By affecting either viral entry ${ }^{31,32}$ or exit $^{33,34}$, these and other proteases could influence viral cellular tropisms and perhaps interactions between glycoprotein domains and antibodies (FICS 2,3). Moreover, Barrientos and Rollin reported recently that endosomal proteolytic enzymes, including cathepsins, were released from EBOV-infected cells, that this release was more pronounced in cells infected with a more lytic variant of EBOV and that cytopathicity was diminished by the cathepsin inhibitor E64 (REF. 35); from this, they inferred a possible role of proteases in pathogenic events including vascular leakage.
Related to all these observations is the abundance of all known cathepsins, especially cathepsin D, cathepsin E and cathepsin $\mathrm{S}$, in monocytes, macrophages and $\mathrm{DC} \mathrm{s}^{36}$, which are cells that are important owing to their great susceptibility to filoviral infection and also owing to the role of their proteases in antigen processing. Interestingly, a variant of EBOV that is resistant to furin cleavage (the same variant noted as being more cytopathic in vivo) was recently reported to be similar to wild-type EBOV in its virulence to non-human primates ${ }^{37}$.

\section{Disordering of adaptive immunity}

Dysfunctional antigen presentation. Generally, properly activated DCs are tailored to evoke optimal activation of $\mathrm{T}$ cells; however during filoviral infection, the functions of DCs might be reversed, as they are first dependant on sensing pathogens through pattern-recognition receptors, and second they are dependant on the signals delivered to them by the viruses. Accordingly, filoviruses have been shown to silence active co-stimulatory molecules in DCs

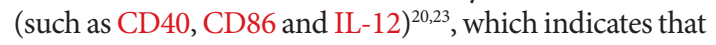
infected DCs enter a stage of cellular dysfunction. In a basic outline, the adaptive immune response can be characterized by the four-part sequence of initial activation, antigen-specific expansion (proliferation), contraction (downsizing) and establishment of immune memory. Filoviruses seem to foster dysregulation of the first three stages and even the fourth might prove problematic for filovirus vaccine development.

Here, we consider that the effects of filoviruses on DCs and monocytes seem to be even more pernicious than those that would result from just the failure to deliver regulated positive immune signals, and that these effects are possibly a result of active co-inhibition of the immune response. The first suggestions of this concept came from the observed clinical manifestations of advanced filoviral diseases in human $\mathrm{s}^{38}$ and mon$\mathrm{keys}^{39}$, in which there were pronounced indications of apoptotic death of lymphocyte populations in peripheral blood and lymph nodes. Because contraction - the loss of some $95 \%$ of cells that had proliferated in response to antigenic stimulation - is a normal part of immune homeostasis ${ }^{40}$, it was unclear at first the degree to which these observations were exaggerated in filoviruses compared with other acute infections. However, the observation aligns with the emerging understanding of co-inhibitory immune signalling, and gives mechanistic support to the hypothesis that filoviruses are among the viruses that can, at least in some species, upset and disorder the natural processes of immune-cell proliferation and contraction.

Role of co-inhibitory molecules in infection. Ordinarily, T-cell co-signalling pathways are stimulated shortly after viral infection - for example, through interactions between the well-characterized co-stimulatory molecule CD28, which is expressed by T cells, and B7-family ligands CD80 and CD86, which are induced on functioning and mature DCs - and they are responsible for activating what is at first a relatively rare population of antigen-specific $\mathrm{T}$ cells. Conversely, these molecules can 


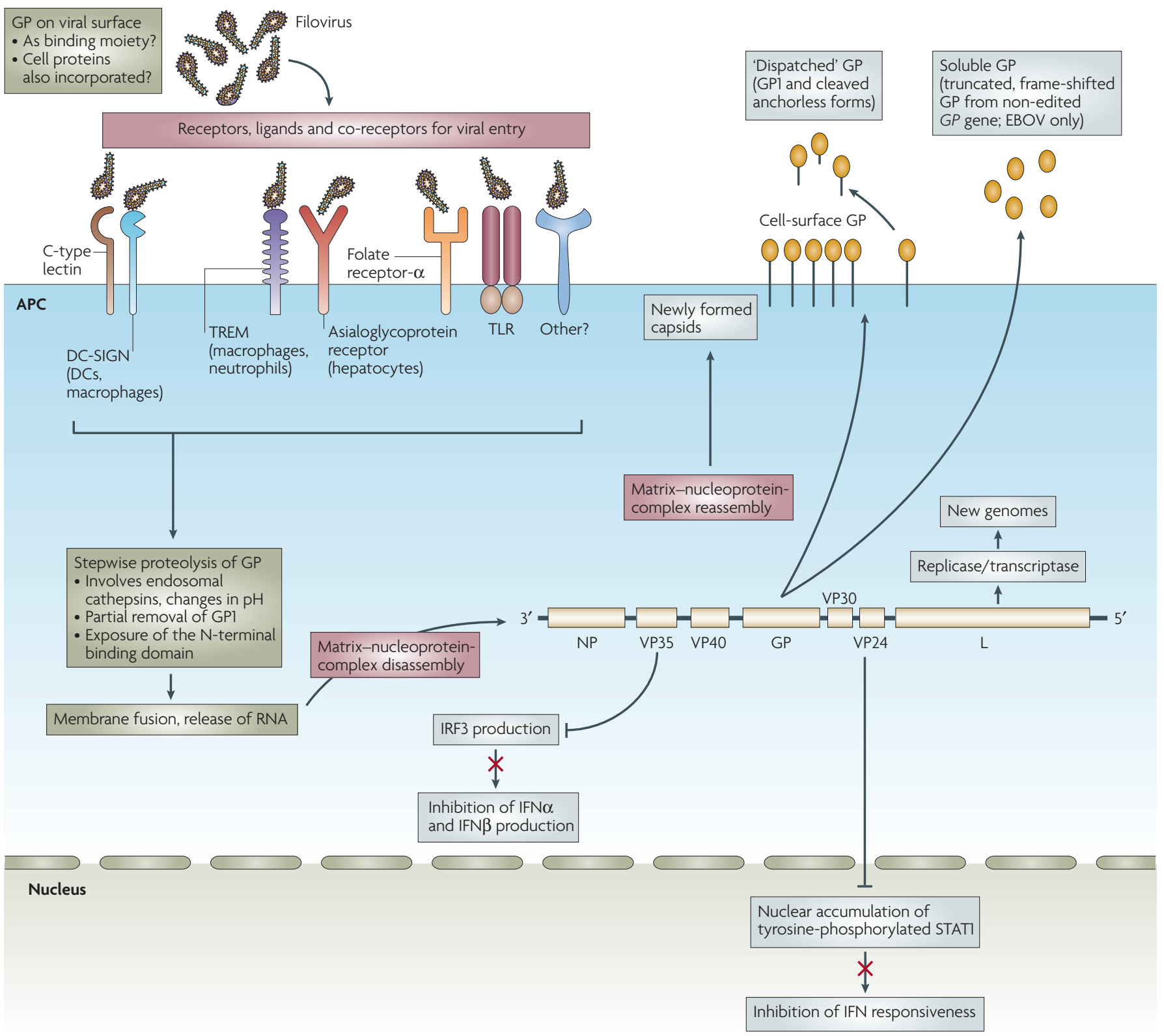

Figure 2 | Viral and cellular events in filoviral infection. Central to filoviral disease is the rapidly increasing viral burden, which can peak at more than $10^{9}$ plaque-forming units (PFUs) in tissues 7-10 days after infection of non-human primates. Several possible cellular receptors for viral entry have been described; these studies have suggested that there is a redundancy in the receptors used for viral entry and that there are partial biases towards the infection of certain cells. Viral entry involves the stepwise proteolysis of viral glycoprotein followed by membrane fusion and disassembly of the elongated matrix-nucleoprotein complex, which contains the other six proteins encoded by the viral genome. In the transcription of mRNAs from the negative-strand genome template, the glycoprotein gene of Ebola virus (EBOV; but not Marburg virus (MARV)) undergoes editing to produce soluble variants of glycoprotein as well as the membrane-bound form, which trimerizes to form the viral envelope spikes. Additional forms of soluble glycoprotein arise post-translationally from proteolysis and/or failure to establish disulphide bonds between naturally occurring glycoprotein fragments GP1 and GP2; the role of soluble forms of glycoprotein in confounding the immune response remains hypothetical. The unchecked replication in primate cells can be explained in large part by the recently described capacity of VP35 to inhibit interferon (IFN)-regulatory factor 3 (IRF3) and thereby prevent infected cells from synthesizing type I IFNs ${ }^{19}$, and the ability of VP24 to interrupt the nuclear accumulation of tyrosine-phosphorylated STAT1 (signal transducer and activator of transcription 1), rendering cells insensitive to the antiviral effects of interferons ${ }^{21}$. EBOV and MARV are cytopathic in most cell types, but direct viral damage to cells is slow enough that host-cell pathways, including protein synthesis, continue to function for many hours, albeit abnormally. After completing the cycle and initiating another, filamentous virions assemble at areas at the plasma membrane called lipid rafts, which are rich in a subset of host-cell proteins. APC, antigen-presenting cell; DC-SIGN, dendritic-cell-specific intercellular adhesion molecule 3 (ICAM3)-grabbing non-integrin; GP, glycoprotein; TLR, Toll-like receptor. 


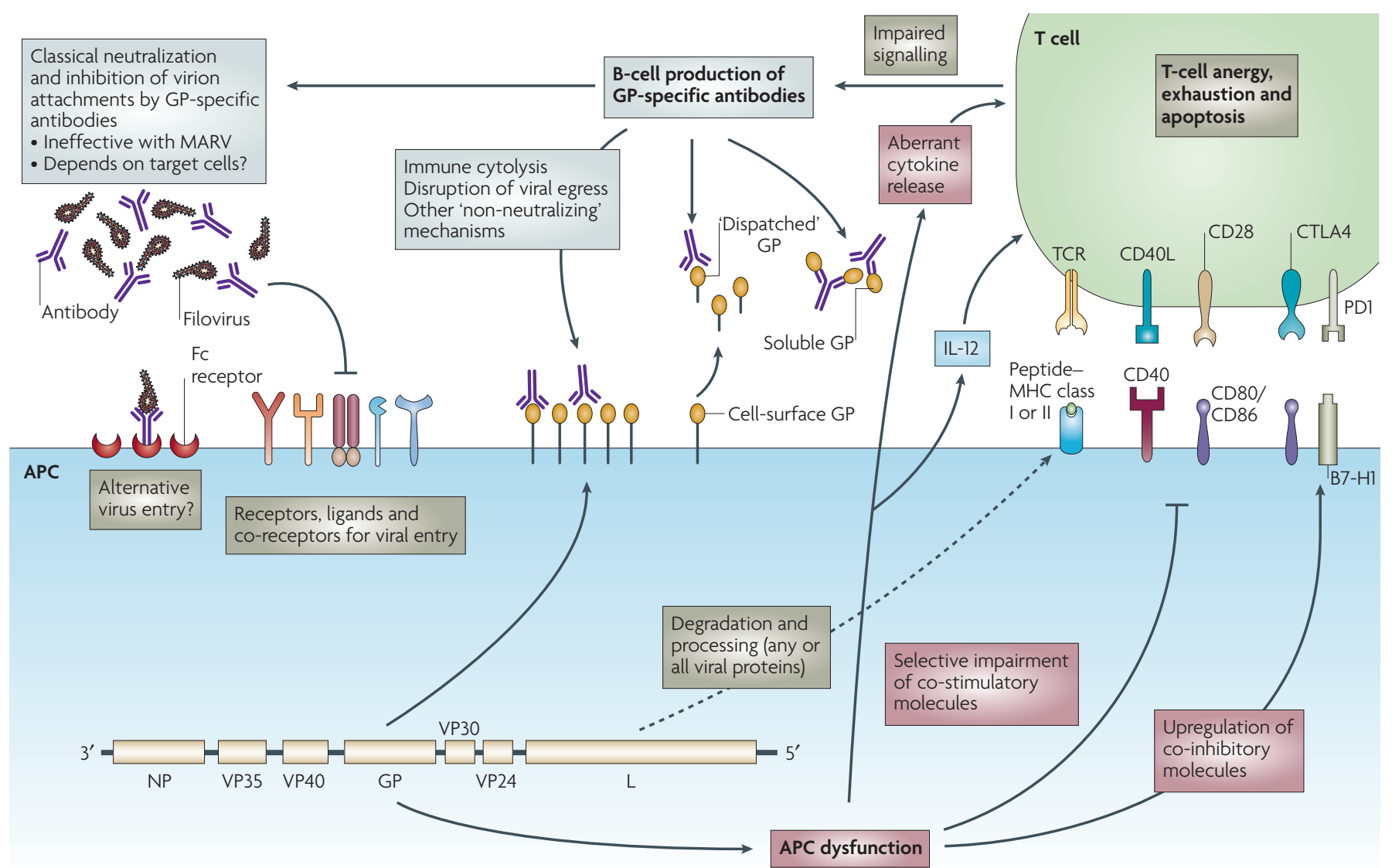

Figure 3 | Effects of filoviral infection on immunological events. Both antibody and T-cell responses (as well as innate effectors such as natural killer (NK) cells) are relevant to immunity and act together to promote viral clearance. Whereas high total antibody levels against glycoprotein are predictive of immunity, serum antibodies of the kind that prevent viral entry (that is, the most familiar type of neutralizing antibody) have proved difficult to measure, especially against Marburg virus (MARV), have been poor correlates of immune protection in vaccination and passive transfer studies. Antibodies might also suppress viral burden by other means, for example, by directing lysis of glycoprotein-expressing cells or disrupting virion formation and release at the cell surface. Hypothetically, soluble forms of glycoprotein are detrimental, having the capacity to sequester antibodies that would otherwise have antiviral effects. T-cell responses are impaired in infected humans and monkeys. Possibly explaining some of the immune deficit, infected human and monkey dendritic cells (DCs) are not only disabled in their interferon (IFN) pathways but are impaired in their capacities to differentiate, express co-stimulatory molecules and produce a normal array of cytokines. Simultaneously, infected DCs and monocytes may express more of the co-inhibitory molecule B7-H1, prompting an increase in its apoptosis-linked receptor programmed cell death 1 (PD1) on T cells. In the resulting model, the adaptive immune response to filoviruses in unvaccinated animals is baffled not only by IFN antagonism in DCs and monocytes but by the viral dysregulation of proinflammatory cytokines, co-stimulatory and co-inhibitory molecules. APC, antigen-presenting cell; CD40L, CD40 ligand; CTLA4, cytotoxic T-lymphocyte antigen 4; GP, glycoprotein; IL-12, interleukin-12, NP, nucleoprotein; TCR, T-cell receptor.

Exhaustion

The condition of functionally impaired antigen-specific T cells, typified by elevated surface expression of PD1. interact with cytotoxic T-lymphocyte antigen 4 (CTLA4) and thereby induce T-cell silencing. Such co-stimulatory and co-inhibitory signals have also been ascribed to other newly described B7-family molecules that are postulated to be crucial in regulating the dialogue between APCs and T cells. This newly described class of the B7 family (including B7-DC (also known as PD-L2 and PDCD1LG2), B7-H1 (also known as PD-L1 and CD274), B7-H2 (also known as ICOSLG), B7-H3 (also known as CD276) and B7-H4 (also known as VTCN1)) and their receptors (such as programmed cell death 1 (PD1; also known as PDCD1) and inducible T-cell co-stimulator (ICOS)) control T-cell responses in both a positive and a negative manner in cancer and infectious diseases ${ }^{41,42}$. In general, co-inhibitory pathways are considered to be among the host mechanisms required to institute or restore homeostasis, minimizing harmful self recognition or re-balancing the system after a robust response to foreign antigen. However, cancer, infectious diseases or autoimmune diseases such as rheumatoid arthritis exploit these processes, and this results in immune evasion, autoreactivity or dysfunctions of immunity, such as anergy and exhaustion ${ }^{41}$.

How might viral-mediated dysfunction of DCs and monocytes be manifested not only as poor positive signalling but as active inhibition of immune responsiveness? An interaction that typifies such inhibition is one that occurs between B7-H1, a co-inhibitory molecule expressed on DCs and monocytes (and many other cells), and its ligand PD1, expressed on activated T and 
B cells. Overexpression of B7-H1 typically precedes the upregulation of PD1 on activated T cells. PD1 then transmits elevated negative signals into T cells, which, in collaboration with unregulated inflammatory cytokines (such as TNF and IFN $\gamma$ ), may effectively establish exhaustion, anergy, and subsequent suppression and apoptosis of these cells ${ }^{40,41,43}$. Indeed, we have previously shown that $\mathrm{B} 7-\mathrm{H} 1$ not only controls $\mathrm{CD}^{+} \mathrm{T}$-cell homeostasis, but also contributes selectively to the deletion of intrahepatic $\mathrm{CD}^{+} \mathrm{T}$ cells ${ }^{44}$. Iwai et al. also showed correlatively that PD1-deficient mice were more resistant to acute hepatic damage owing to adenovirus infection ${ }^{45}$. Moreover, Barber et al. recently showed that although most lymphocytic choriomeningitis virus (LCMV)specific $\mathrm{CD}^{+} \mathrm{T}$ cells in persistently infected mice express activation molecules (such as CD69 and CD44), these cells are functionally exhausted and therefore do not exert their antiviral effector function ${ }^{46}$. Barber et al. further showed that PD1 is expressed on impaired LCMV-specific CD8 ${ }^{+} \mathrm{T}$ cells and that blockage of the PD1 interaction with B7-H1 during chronic LCMV infection reanimates these cells and induces clearance of $\mathrm{LCMV}^{46}$. These trends have been confirmed in human studies showing that elevated levels of B7-H1 (REF. 47) and PD1 (REFS 48,49) are associated with T-cell exhaustion and depletion in HIV, and T-cell function can be restored in vitro by using B7-H1-specific antibody to antagonize the co-inhibitory interaction between B7-H1 and PD1. The commonality between these and other earlier observations of the importance of co-inhibition mediated by B7-H1-PD1 interactions is that they involve chronic conditions.

Returning to the particular case of filoviruses and the acute diseases that they cause, recent investigations in individuals and non-human primates infected with filoviruses have demonstrated the gradual disappearance and deletion of $\mathrm{CD}^{+} \mathrm{T}$ cells and $\mathrm{NK}$ cells ${ }^{38,50}$. That little or no immune response to the virus is observed in humans and non-human primates before they succumb to disease ${ }^{4,6,51}$ is consistent with the incapacity of infected DCs to regulate their CD40 and CD86 molecules, and the coincident failure of DCs to secrete IL-12 and other cytokines ${ }^{20,23}$. The naturally increased expression of B7-H1 in liver macrophages and parenchymal cells - thought to explain, at least in part, the poor immune responses to a wide range of antigens typically observed in the liver ${ }^{44}$ - is particularly intriguing in view of the hepatotropic manifestation of filoviral disease (FIG. 1, BOX 1). For now, because immune dysfunction that is directly attributable to the rapid triggering of co-inhibitory pathways is only beginning to be implicated in acute viral infections ${ }^{42}$, the importance of this pathway in filovirus pathogenesis remains speculative.

Paradoxically, the role of IFN $\gamma$, which is secreted copiously in the plasma of infected individuals and non-human primates late in filovirus infection ${ }^{8,52}$, might be more detrimental than helpful, as any regulatory effects of IFN $\gamma$ on $\mathrm{CD}^{+} \mathrm{T}$ cells must be proximal to initial activation; otherwise, this cytokine might induce pro-apoptotic effects that result in cell-population contraction and T-cell apoptosis ${ }^{53}$. Although CD8 ${ }^{+}$
T cells have mechanisms to evade this cytokine by downregulating the IFN $\gamma$ receptor subunit 2 to complete their cellular expansion ${ }^{54}$, the rapid filoviral invasion might induce other unknown signalling events that might close the window of opportunity to promote functional $\mathrm{CD} 8^{+} \mathrm{T}$ cells. Moreover, what are the roles of other regulatory and inflammatory molecules (such as IL-10, transforming growth factor- $\beta 1$ (TGF $\beta 1$ ) and IL-17), which are abundantly secreted during the induction phase of filoviral infection? Answers will come as future studies shed light on additional aspects of filoviral infection and disease.

Other immune-component cells. In addition to NK cells, filoviruses might also trigger CD1d-restricted $i$ NKT cells ${ }^{55,56}$, and even IFN-producing killer DCs (IKDCs), a newly described DC subset in which the cells have characteristics of both DCs and NK cells ${ }^{57}$. The resulting signalling cascade would involve massive detrimental inflammation, dysfunction of DCs, retention of DCs in an immature stage and abolition of the co-stimulatory function of DCs; therefore, NK cells or $i$ NKT cells would not be able to exercise effective responses to invading filoviruses. Worse, on receiving co-inhibitory signals, these cells might contribute to the production of copious amounts of IFN $\gamma$, which can induce more B7-H1 (REF. 58) and thus facilitate further cellular anergy and subsequent NK-cell deletion ${ }^{38,50}$. Conversely, as filovirally infected DCs retain an immature phenotype, these cells could be eliminated by the NK-cell-dependent NKp30 trigger receptor ${ }^{59}$. Further fundamental questions remain to be addressed to understand what mediates the impaired cytotoxicity of NK cells, $i$ NKT cells or even IKDCs, and to discern the factors that are induced by dysfunctional DCs and the strong inflammatory microenvironment that occurs early during the infection, wherein these cells reside.

Collectively, therefore, much remains to be clarified with respect to the relative importance of new or dysregulated pathways in the innate and adaptive immune responses to filoviruses. However, recent studies point towards what might be reversible dysfunctions and therefore to new therapeutic rationales to restore balance and favour an animal's survival.

\section{Inferences from vaccines and therapies}

Filovirus antigens. Filoviruses belong to the order of Mononegavirales, which includes respiratory syncytial, measles, mumps, parainfluenza and rabies viruses. As antigens, filoviruses have a uniquely filamentous structure, but at a glance otherwise seem to be unexceptional among similar viral genera. That is, from a single 19-kilobase strand of negative-sense RNA, the viral replicase complex makes mRNA to encode relatively few (seven or more) proteins (FIG. 2). Of these, only one (the glycoprotein) is known with certainty to appear on virion surfaces (and also on the surface of infected cells), where it can serve as a target for antibodies, some of which might mediate protection. In theory, any of these viral proteins could be recognized by $\mathrm{T}$ cells; indeed, in the case of a mouse-adapted variant of 
Table 1 | Marburg- and Ebola-virus vaccines containing glycoprotein

\begin{tabular}{|c|c|c|c|}
\hline Vaccine type* & Comments & Principal concerns & Refs \\
\hline Killed filovirus & $\begin{array}{l}\text { Early vaccine efforts and recent proofs of concept; inadequate efficacy }{ }^{\ddagger} \\
\text { in non-human primates }\end{array}$ & $\begin{array}{l}\text { Safety } \S^{\S} \text {; potency"; observed disease } \\
\text { exacerbation }\end{array}$ & $67,68,94$ \\
\hline $\begin{array}{l}\text { Live attenuated } \\
\text { filovirus }\end{array}$ & $\begin{array}{l}\text { Only as proofs of concept with natural or passaged viruses; high risk } \\
\text { could theoretically be mitigated by reverse-genetics approach }\end{array}$ & $\begin{array}{l}\text { Live vaccine; balance of safety and } \\
\text { potency incomplete attenuation or } \\
\text { reversion }\end{array}$ & $94-97$ \\
\hline $\begin{array}{l}\text { Live vaccinia } \\
\text { vectored }\end{array}$ & $\begin{array}{l}\text { oof of concept, deprioritized along with other live pox-vectored } \\
\text { ccines }\end{array}$ & $\begin{array}{l}\text { Live vaccine balance of safety and } \\
\text { potency; vector immunity }\end{array}$ & 67 \\
\hline $\begin{array}{l}\text { Defective VEE } \\
\text { replicon }\end{array}$ & $\begin{array}{l}\text { Excellent efficacy in rodents, first demonstration of efficacy against } \\
\text { MARV in non-human primates, minimum protective dose about } 10^{8} \mathrm{IU} \\
\text { in non-human primates }\end{array}$ & $\begin{array}{l}\text { Vector immunity; safety at doses high } \\
\text { enough to achieve potency }\end{array}$ & $4,62,94$ \\
\hline DNA & $\begin{array}{l}\text { Adequate in rodents; incomplete non-human-primate efficacy with } \\
\text { MARV and none reported with EBOV; touted for immunological } \\
\text { priming }\end{array}$ & Potency & $\begin{array}{r}63,78,79 \\
94,99\end{array}$ \\
\hline $\begin{array}{l}\text { Virus-like } \\
\text { particles }\end{array}$ & $\begin{array}{l}\text { Good rodent efficacy; safety and possible potency advantage } \\
\text { compared with killed virus particles }\end{array}$ & t requirement & 101 \\
\hline $\begin{array}{l}\text { Live recombinant } \\
\text { VSV }\end{array}$ & $\begin{array}{l}\text { Excellent rodent and non-human-primate efficacy with both MARV and } \\
\text { EBOV; single-shot vaccine, rapid immunity; no overt illness from live } \\
\text { vaccine itself; in recombinant vaccine, filovirus glycoprotein replaces } \\
\text { VSV glycoprotein }\end{array}$ & $\begin{array}{l}\text { Live vaccine; balance of safety and } \\
\text { potency; environmental release }{ }^{\star *}\end{array}$ & 64,82 \\
\hline $\begin{array}{l}\text { Live recombinant } \\
\text { parainfluenza }\end{array}$ & $\begin{array}{l}\text { Good efficacy against Ebola virus in guinea pigs and non-human } \\
\text { primates; contains both parainfluenza virus and EBOV glycoproteins }\end{array}$ & $\begin{array}{l}\text { Live vaccine; balance of safety and } \\
\text { potency; environmental release }\end{array}$ & 80,81 \\
\hline \multicolumn{4}{|c|}{ 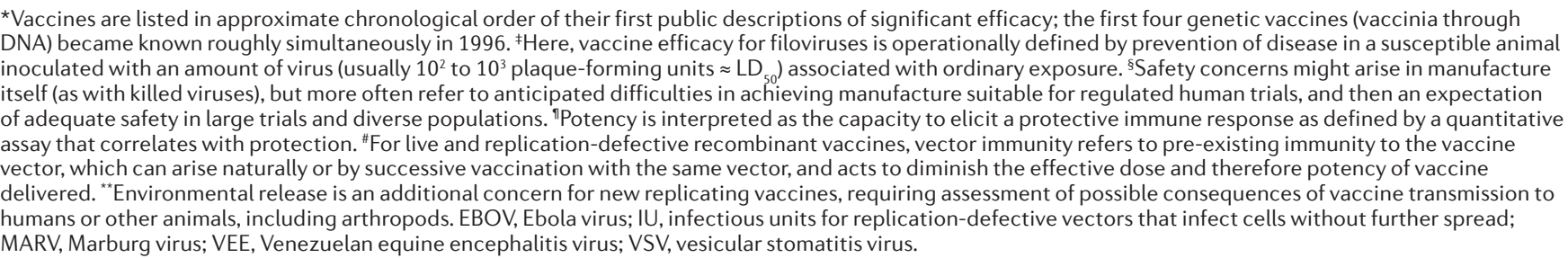 } \\
\hline
\end{tabular}

Zaïre ebolavirus (ZEBOV), six of the seven existing proteins (the replicase protein $\mathrm{L}$ was not examined) were observed to evoke protective responses in at least one strain of mouse, with demonstrable T-cell responses associated with survival, and, in some cases, effective on adoptive transfer ${ }^{60,61}$. However, in guinea pigs challenged with MARV, only viral glycoprotein, nucleoprotein and VP35 afforded some measure of protection when used as vaccines in a replicon-based vector system ${ }^{4}$. In guinea pigs vaccinated and then challenged with ZEBOV, viral glycoprotein was a superior protective antigen, with nucleoprotein providing no ${ }^{62}$ or equivocal ${ }^{63}$ protection. In the case of non-human primates that had been vaccinated and then challenged with either MARV or ZEBOV, viral glycoprotein has proved to be necessary and sufficient as a vaccine component. Nucleoprotein alone provided incomplete protection in monkeys infected with MARV, whereas viral glycoprotein by itself (or admixed with nucleoprotein) prevented illness and death in six out of six infected animals ${ }^{4}$. Similarly, the first successes in protecting non-human primates against ZEBOV were with a vaccine containing glycoprotein; subsequent studies showed glycoprotein by itself to be sufficient ${ }^{64,65}$, and there are no published data to indicate that there are any other proteins capable of protecting non-human primates against ZEBOV in the absence of glycoprotein.

It is frequently observed that filoviral vaccines and therapies that succeed in rodents are far less successful in non-human primates ${ }^{4,8,66-68}$. Therefore, the collective and empirical experience with vaccines tested for the capacity to protect against either MARV or ZEBOV in the most susceptible and perhaps most relevant (to humans) host - non-human primates - has revolved entirely around vaccines that contain glycoprotein (TABLE 1). Whether filovirus vaccines for non-human primates can be improved by removing some regions of glycoprotein remains to be shown.

Humoral immunity against filovirus infection. Mechanistically, most of the available evidence indicates that both antibody and T-cell responses of appropriate kind and magnitude are required for robust protection against filoviruses, especially in non-human primates. Support for the involvement of antibodies takes several forms. Foremost, passive immunotherapy with convalescent sera or monoclonal antibodies has been shown to mitigate or prevent MARV and ZEBOV disease in 
guinea pigs and mice ${ }^{69-72}$, delay viraemia and death in non-human primates ${ }^{27}$ and possibly improve clinical outcomes in humans ${ }^{73,74}$. Moreover, B-cell-deficient mice were impaired in their ability to eliminate $\mathrm{ZEBOV}^{75}$. Further, the empirical observation of glycoprotein as the most effective protective antigen in non-human primates argues indirectly that humoral immunity is relevant, and protection has been associated with total antibody levels ${ }^{4,64,65}$.

On the other hand, antibody alone has not yet been shown to be sufficient to protect non-human primates from lethal infection with more than a few infectious viruses $^{27,76}$, and the human clinical data were equivocal because treatments were performed in uncontrolled emergency situations. It has been confounding to some researchers that neutralization of filoviruses by antibodies - as measured by a reduction in viral infectivity after admixture with antibodies - has proved to be a completely unreliable in vitro predictor of antibody or vaccine effectiveness ${ }^{4,64,70,76}$. Others researchers point to a rich history of antibodies shown to protect in ways other than what is popularly understood as neutralization ${ }^{77}$. Some of the mechanisms by which such non-neutralizing antibodies might control viral burden are shown in FIG. 3 and are briefly reviewed elsewhere ${ }^{77}$. It remains unclear whether monoclonal antibodies can be found to act by themselves therapeutically in non-human primates, whether other strategies will prove more effective (BOX 2), or whether combination therapies, perhaps including antibodies, will be required.

Cellular immunity to filovirus infection. The role of T cells in successful vaccination against filoviruses is similarly persuasive, yet insufficient to attribute this protection wholly to cellular immunity. T-cell involvement has been documented most clearly in the mouse model of ZEBOV, in which cytotoxic $\mathrm{T}$ cells specific for nucleoprotein were protective on adoptive transfer ${ }^{61}, \mathrm{CD}^{+} \mathrm{T}$-cell-deficient mice were more susceptible to lethal challenge ${ }^{75}$ and at least five cytoplasmic ZEBOV proteins (presumably inaccessible to antibodies) were independently capable of eliciting both $\mathrm{T}$ cells and protective immunity ${ }^{60}$. Internal nucleoprotein and VP35 were capable of inducing significant protection in MARV-infected guinea pigs $^{4}$, and the nucleoprotein-specific protection in non-human primates was probably due to $\mathrm{T}$ cells ${ }^{4}$. In an effort to discern how mice resist $\mathrm{ZEBOV}$, a case was made that not only $\mathrm{CD}^{+}$ $\mathrm{T}$ cells but also $\mathrm{CD} 4^{+} \mathrm{T}$ cells are crucial in viral clearance $^{75}$, a finding that would be among those expected if glycoprotein-specific antibodies were important. Reliable quantification of $\mathrm{T}$-cell responses in a way that correlates with protection has not been achieved with filoviruses in guinea pigs or non-human primates, but when serious efforts to measure T-cell responses have been undertaken, it has been routinely observed that filovirus-antigenspecific $\mathrm{T}$ cells can be found in animals that are shown subsequently to be immune to lethal infection ${ }^{78}$.

A collective analysis of the vaccine studies in TABLE 1 indicates that the magnitude of the total glycoproteinspecific antibody response is associated with protection, a measure which presumably correlates not only with types of antibody that are protective but also with T cells for which suitable assays remain elusive. Put most simply, higher doses of vaccine seem to evoke greater total immune responses, along with a protection that is more rapidly acquired and more complete than that obtained with replication-defective vaccines given at much lower doses. A recent report with a recombinant adenovirus that expresses the ZEBOV glycoprotein, in which the minimal protective dose of $10^{10}$ particles is described as a 'low dose', affirms that protection is dependent on the vaccine dose $e^{65}$, and might explain why repliconbased vaccines given at much lower doses have not been uniformly successful ${ }^{67}$ and DNA vaccines have been only partially effective ${ }^{79}$. Live vesicular stomatitis virus $(\mathrm{VSV})^{64}$ or parainfluenza virus ${ }^{80,81}$ recombinants, which show considerable promise in protecting non-human primates from filoviral infection, presumably generate high amounts of viral glycoprotein antigen in vivo. Herein resides a most familiar challenge of vaccine licensure: the achievement of a suitable balance between vaccine potency and vaccine safety.

Mechanistically, additional immunological and virological puzzles have been exposed by recent demonstrations of protective effects of vaccinating rodents or primates with replication-competent vaccines shortly before or shortly after infection with $\mathrm{MARV}^{82}$ or $\mathrm{EBOV}^{83}$. Surmising that protective mechanisms in this exceptional circumstance could be 'multifactorial', Feldmann et al. proposed as possible explanations not only antibodies and T cells, but also NK cells, innate immune responses and viral interference (attenuated-vaccine virus out-competing virulent filoviruses at the cellular level $)^{83}$. Hypothetically, well-balanced innate and adaptive immune responses against the replicating vaccine (here in a VSV vector) occur in parallel with otherwise dysfunctional responses to filoviruses, suppressing and ultimately eliminating both viruses. Whether replicationdefective filovirus vaccines may have similar protective effects if given shortly before or after filoviral infection is not yet clear.

Difficulties presented to the immune system by filoviral glycoprotein antigens. If it were not difficult enough for the immune system to repel filoviral attack, viral glycoprotein presents an array of deceptions and challenges. Summarized in TABLE 2, the confounding traits of viral glycoprotein influence the rational design and improvement of vaccines. Moreover, although several experimental vaccine approaches have been shown to be capable of eliciting the robust immune responses necessary to protect non-human primates against either EBOV or MARV disease, it remains to be determined whether appropriate immunological memory (as defined by long-term protection) will be established by the same vaccines. As for the immune systems of the unvaccinated primates exposed to glycoprotein for the first time, and in the context of all the aforementioned advantages held by the infectious virus, it is perhaps most impressive that the immune response occasionally prevails, and many individuals and a few non-human primates do survive. 


\section{Table 2 | Evasion and deception strategies available to filovirus glycoprotein}

\begin{tabular}{|c|c|c|c|}
\hline Observation & Comments & Immune consequences & Refs \\
\hline Antigenic variation & $\begin{array}{l}\text { Variability between isolates and species is } \\
\text { concentrated in the central 'mucin-like' portion of GP, } \\
\text { which, after cleavage to GP1-GP2 becomes the distal } \\
\text { aspect of the GP spike }\end{array}$ & $\begin{array}{l}\text { Negligible cross-reactivities of antibodies and no } \\
\text { cross-protection between viral species, limited cross- } \\
\text { reactivities of antibodies among disparate isolates of } \\
\text { MARV }\end{array}$ & $\begin{array}{r}15,69,70 \\
102,103\end{array}$ \\
\hline $\begin{array}{l}\text { Abundant } \mathrm{N} \text { - and } \\
\text { O-linked glycosylation }\end{array}$ & $\begin{array}{l}\text { Concentrated in mucin-like domain; variations in } \\
\text { glycosylation, some due to cell type }\end{array}$ & $\begin{array}{l}\text { Epitope masking; phenotypic variation; viral tropism } \\
\text { for cells having lectin-like receptors (such as DCs and } \\
\text { monocytes) }\end{array}$ & $\begin{array}{r}11,15 \\
69,104\end{array}$ \\
\hline GP gene editing & $\begin{array}{l}\text { Observed in EBOV, not MARV; genome encodes } \\
\text { mRNA for a truncated, frame-shifted version of GP } \\
\text { (sGP) }\end{array}$ & $\begin{array}{l}\text { Similar to GP shedding, but with added twists of } \\
\text { truncation, frame-shift and different glycosylation of } \\
\text { sGP }\end{array}$ & $\begin{array}{r}97,105, \\
106\end{array}$ \\
\hline $\begin{array}{l}\text { Structural masking of } \\
\text { receptor-binding and } \\
\text { fusion domains }\end{array}$ & $\begin{array}{l}\text { Key functional domains are proximal to membrane, } \\
\text { exposed only transiently upon entry }\end{array}$ & $\begin{array}{l}\text { Antibodies underrepresented and possibly ineffective } \\
\text { against important functional regions }\end{array}$ & $\begin{array}{r}32, \\
107-109\end{array}$ \\
\hline $\begin{array}{l}\text { Triggering of cytokine } \\
\text { release }\end{array}$ & $\begin{array}{l}\text { GP on viral particles is sufficient to trigger } \\
\text { intracellular cascades, granule release, cytokines }\end{array}$ & $\begin{array}{l}\text { Disorienting milieu for initiation of balanced immune } \\
\text { response }\end{array}$ & $\begin{array}{l}12,20,23 \\
25,51,52\end{array}$ \\
\hline Toxicity of GP for cells & $\begin{array}{l}\text { Might be less of a problem in vivo than with in vitro } \\
\text { expression systems }\end{array}$ & $\begin{array}{l}\text { Could affect performance or manufacture of genetic } \\
\text { vaccines }\end{array}$ & $\begin{array}{r}97,110 \\
111\end{array}$ \\
\hline $\begin{array}{l}\text { Immunosuppressive } \\
\text { domain }\end{array}$ & $\begin{array}{l}\text { Tenuous observation, with importance still neither } \\
\text { confirmed nor refuted }\end{array}$ & $\begin{array}{l}\text { Remains a possible explanation for some } \\
\text { dysregulations now attributed to whole GP }\end{array}$ & 68,112 \\
\hline
\end{tabular}

EBOV, Ebola virus; GP, glycoprotein; MARV, Marburg virus; sGP, soluble GP.

\section{Concluding hypotheses and prospects}

It is becoming progressively clearer how EBOV and MARV overwhelm host defences and cause disease by dysregulating and defeating first the innate and then the adaptive immune systems of primates and humans (FICS 1-3). Each of several properties of the viruses are probably required to account for their profound virulence, and it has already been observed that changes in the IFN antagonists VP35 and VP24, the glycoprotein, the viral replicase or the nucleoprotein can diminish filovirus virulence in the mouse model ${ }^{84}$. It remains to be explained why the profound virulence, characteristic of all members of the diverse family Filoviridae, is apparently limited to primates ${ }^{85}$, which are presumably accidental hosts for the viruses. Nonetheless, our increased understanding of the events involved in filoviral infection points towards new possibilities in shifting the advantage to the immune system. In general, the many therapeutic approaches designed to slow viral replication can allow the immune system to gain additional time to mount an effective defence, but such intervention might be required early, even before symptoms develop.
Other interventions, intended to manage disease symptoms, might also provide the immune system with additional time. One possibility that has emerged is an intentional intervention in the early inflammation and co-inhibitory dialogue between DCs and $\mathrm{T}$ cells and even other immune-cell types, for example, with specific tolls (such as B7-H1-specific antibody) to prevent exaggerated regulatory signals from inducing T-cell exhaustion; this hypothetical means to control viral clearance has precedence in cancer, $\mathrm{HIV}$ and, more recently, in a mouse model of chronic lymphocytic choriomeningitis virus infection ${ }^{41,43,46,86}$. Improvements in filoviral vaccine development strategies might follow from the ongoing identification and exploitation of glycoprotein components that evoke protective immunity. On the whole, the efforts to provide medical countermeasures for these deadly but relatively rare viruses seem poised to tell us a great deal not only about these particular viruses, but more generally about the immune responses to acute viral infections, and how to shift the battle in favour of immunity and survival.
1. Feldmann, H. et al. Filovirus-induced endothelial leakage triggered by infected monocytes/ macrophages. J. Virol. 70, 2208-2214 (1996)

2. Wahl-Jensen, V. et al. Role of Ebola virus secreted glycoproteins and virus-like particles in activation of human macrophages. J. Virol. 79, 2413-2419 (2005)

3. Slenczka, W. G. The Marburg virus outbreak of 1967 and subsequent episodes. Curr. Top. Microbiol. Immunol. 235, 49-75 (1999).
4. Hevey, M., Negley, D., Pushko, P., Smith, J. \& Schmaljohn, A. Marburg virus vaccines based upon alphavirus replicons protect guinea pigs and nonhuman primates. Virology 251, 28-37 (1998).

This reference provides a seminal demonstration of glycoprotein as a necessary and sufficient protective antigen, and of a vaccine capable of providing robust immunity against filovirus disease in non-human primates.

5. Ryabchikova, E. I., Kolesnikova, L. V. \& Luchko, S. V. An analysis of features of pathogenesis in two animal models of Ebola virus infection. J. Infect. Dis. 179 (Suppl. 1), 199-202 (1999).

6. Ignatyev, G. M. Immune response to filovirus infections. Curr. Top. Microbiol. Immunol. 235, 205-217 (1999). 
7. Geisbert, T. W. et al. Pathogenesis of Ebola hemorrhagic fever in cynomolgus macaques: evidence that dendritic cells are early and sustained targets of infection. Am. J. Pathol. 163, 2347-2370 (2003).

This paper reports distinctive in vivo studies in which early viral events in non-human primates were tracked in serial sampling experiments.

8. Feldmann, H., Jones, S., Klenk, H. D. \& Schnittler, H. J. Ebola virus: from discovery to vaccine. Nature Rev. Immunol. 3, 677-685 (2003).

9. Simmons, G. et al. DC-SIGN and DC-SIGNR bind Ebola glycoproteins and enhance infection of macrophages and endothelial cells. Virology 305, 115-123 (2003).

10. Takada, A. et al. Human macrophage C-type lectin specific for galactose and $\mathrm{N}$-acetylgalactosamine promotes filovirus entry. J. Virol. 78, 2943-2947 (2004).

11. Becker, S., Spiess, M. \& Klenk, H. D. The asialoglycoprotein receptor is a potential liverspecific receptor for Marburg virus. J. Gen. Virol. 76, 393-399 (1995)

12. Mohamadzadeh, M. et al. Activation of triggering receptor expressed on myeloid cells- 1 on human neutrophils by Marburg and Ebola viruses. J. Virol. 80, 7235-7244 (2006).

13. Bobardt, M. D. et al. Syndecan captures, protects, and transmits HIV to T lymphocytes. Immunity 18, 27-39 (2003).

14. Chan, S. Y. et al. Folate receptor- $\alpha$ is a cofactor for cellular entry by Marburg and Ebola viruses. Cell 106, 117-126 (2001).

15. Feldmann, H., Nichol, S. T., Klenk, H. D., Peters, C. J. $\&$ Sanchez, A. Characterization of filoviruses based on differences in structure and antigenicity of the virion glycoprotein. Virology 199, 469-473 (1994).

16. Bavari, S. et al. Lipid raft microdomains: a gateway for compartmentalized trafficking of Ebola and Marburg viruses. J. Exp. Med. 195, 593-602 (2002).

17. Mohamadzadeh, M., Chen, L., Olinger, G. G. Pratt, W. D. \& Schmaljohn, A. Filoviruses and the balance of innate, adaptive, and inflammatory responses. Viral Immunol. 19, 602-612 (2006).

18. Groot, F. et al. Lactoferrin prevents dendritic cell-mediated human immunodeficiency virus type 1 transmission by blocking the DC-SIGN-gp 120 interaction. J. Virol. 79, 3009-3015 (2005)

19. Cardenas, W. B. et al. Ebola virus VP35 protein binds double-stranded RNA and inhibits $\alpha / \beta$ interferon production induced by RIG-I signaling. J. Virol. 80, 5168-5178 (2006).

Along with reference 21 , this paper provides recent mechanistic data and an overview on IFN antagonists encoded by filoviruses.

20. Bosio, C. M. et al. Ebola and Marburg viruses replicate in monocyte-derived dendritic cells without inducing the production of cytokines and full maturation. J. Infect. Dis. 188, 1630-1638 (2003).

21. Reid, S. P. et al. Ebola virus VP24 binds karyopherin $\alpha 1$ and blocks STAT 1 nuclear accumulation. J. Virol. 80, 5156-5167 (2006)

22. Marrack, P., Kappler, J. \& Mitchell, T. Type I interferons keep activated T cells alive. J. Exp. Med. 189, 521-530 (1999).

23 Mahanty, S. et al. Cutting edge: impairment of dendritic cells and adaptive immunity by Ebola and Lassa viruses. J. Immunol. 170, 2797-2801 (2003).

24. Gupta, M., Mahanty, S., Ahmed, R. \& Rollin, P. E. Monocyte-derived human macrophages and peripheral blood mononuclear cells infected with Ebola virus secrete MIP- $1 \alpha$ and TNF- $\alpha$ and inhibit poly-IC-induced IFN- $\alpha$ in vitro. Virology 284, 20-25 (2001).

25. Ströher, U. et al. Infection and activation of monocytes by Marburg and Ebola viruses. J. Virol. 75, 11025-11033 (2001)

26. Warfield, K. L. et al. Role of natural killer cells in innate protection against lethal Ebola virus infection. J. Exp. Med. 200, 169-179 (2004).

27. Jahrling, P. B. et al. Evaluation of immune globulin and recombinant interferon- $\alpha 2 \mathrm{~b}$ for treatment of experimental Ebola virus infections. J. Infect. Dis. 179 (Suppl 1), 224-234 (1999).

28 Kash, J. C. et al. Global suppression of the host antiviral response by Ebola- and Marburgviruses: increased antagonism of the type I interferon response is associated with enhanced virulence. J. Virol. 80, 3009-3020 (2006)

29. Khabar, K. S. et al. The $\alpha$ chemokine, interleukin 8 , inhibits the antiviral action of interferon $\alpha$ J. Exp. Med. 186, 1077-1085 (1997).
30. Nathan, C. Neutrophils and immunity: challenges and opportunities. Nature Rev. Immunol. 6, 173-182 (2006).

This is a timely and highly readable review of the sometimes neglected importance of neutrophils in innate and adaptive immunity.

31. Chandran, K., Sullivan, N. J., Felbor, U., Whelan, S. P. \& Cunningham, J. M. Endosomal proteolysis of the Ebola virus glycoprotein is necessary for infection. Science 308, 1643-1645 (2005).

32. Schornberg, K. et al. Role of endosomal cathepsins in entry mediated by the Ebola virus glycoprotein. J. Virol. 80, 4174-4178 (2006)

33. Dolnik, O. et al. Ectodomain shedding of the glycoprotein $\mathrm{GP}$ of Ebola virus. EMBO J. 23, 2175-2184 (2004)

34. Sanchez, A. et al. Biochemical analysis of the secreted and virion glycoproteins of Ebola virus. J. Virol. 72, 6442-6447 (1998).

35. Barrientos, L. G. \& Rollin, P. E. Release of cellular proteases into the acidic extracellular milieu exacerbates Ebola virus-induced cell damage. Virology 358, 1-9 (2007).

36. Mohamadzadeh, M., Mohamadzadeh, $\mathrm{H}$, Brammer, M., Sestak, K. \& Luftig, R. B. Identification of proteases employed by dendritic cells in the processing of protein purified derivative (PPD). J. Immune Based Ther. Vaccines 2, 8 (2004).

37. Neumann, G. et al. Proteolytic processing of the Ebola virus glycoprotein is not critical for Ebola virus replication in nonhuman primates. J. Virol. 81, 2995-2998 (2007)

38. Baize, S. et al. Defective humoral responses and extensive intravascular apoptosis are associated with fatal outcome in Ebola virus-infected patients. Nature Med. 5, 423-426 (1999).

39. Geisbert, T. W. et al. Apoptosis induced in vitro and in vivo during infection by Ebola and Marburg viruses. Lab. Invest. 80, 171-186 (2000)

40. Haring, J. S., Badovinac, V. P. \& Harty, J. T. Inflaming the $\mathrm{CD}^{+}{ }^{+} \mathrm{T}$ cell response. Immunity $25,19-29$ (2006)

41. Chen, L. Co-inhibitory molecules of the B7-CD28 family in the control of T-cell immunity. Nature Rev Immunol 4, 336-347 (2004).

This review describes co-signalling molecules, a class of cell-surface glycoproteins that direct, modulate and fine-tune the TCR, and summarizes data indicating that T-cell functions can be promoted or suppressed on the basis of the functional outcome of co-stimulatory or co-inhibitory signals. The author emphasizes the appropriate time and location of these molecules directing either positive or negative signals to control priming, growth, differentiation and functional maturation of a T-cell immune response.

2. Sharpe, A. H., Wherry, E. J., Ahmed, R. \& Freeman, G. J. The function of programmed cell death 1 and its ligands in regulating autoimmunity and infection. Nature Immunol 8, 239-245 (2007).

This authoritative recent review highlights the crucial functions of PD1 and its ligands (PDL1 and PDL2) in regulating antimicrobial and self-reactive T-cell immune responses, and discusses potential therapeutic strategies in manipulating the immunological outcomes of such interactions.

43. Carreno, B. M., Carter, L. L. \& Collins, M. Therapeutic opportunities in the B 7/CD28 family of ligands and receptors. Curr. Opin. Pharmacol. 5, 424-430 (2005)

44. Dong, H. et al. B7-H1 determines accumulation and deletion of intrahepatic CD8 ${ }^{+} \mathrm{T}$ lymphocytes. Immunity 20, 327-336 (2004)

45. Iwai, Y., Terawaki, S., Ikegawa, M., Okazaki, T. \& Honjo, T. PD-1 inhibits antiviral immunity at the effector phase in the liver. J. Exp. Med. 198, 39-50 (2003)

46. Barber, D. L. et al. Restoring function in exhausted CD8 T cells during chronic viral infection. Nature 439, 682-687 (2006)

47. Trabattoni, D. et al. B7-H1 is up-regulated in HIV infection and is a novel surrogate marker of disease progression. Blood 101, 2514-2520 (2003).

48. Trautmann, L. et al. Upregulation of PD-1 expression on HIV-specific CD8 ${ }^{+} \mathrm{T}$ cells leads to reversible immune dysfunction. Nature Med. 12, 1198-1202 (2006)

49. Day, C. L. et al. PD-1 expression on HIV-specific T cells is associated with T-cell exhaustion and disease progression. Nature 443, 350-354 (2006).
50 Reed, D S ., Hensley, L. E Geisbert, J. B., Jahrling, P. B \& Geisbert, T. W. Depletion of peripheral blood T lymphocytes and NK cells during the course of Ebola hemorrhagic fever in cynomolgus macaques. Viral Immunol. 17, 390-400 (2004).

51. Leroy, E. M. et al. Human asymptomatic Ebola infection and strong inflammatory response. Lancet 355, 2210-2215 (2000)

52. Baize, S. et al. Inflammatory responses in Ebola virusinfected patients. Clin. Exp. Immunol. 128, 163-168 (2002).

53. Badovinac, V. P. \& Harty, J. T. Programming, demarcating, and manipulating CD8 ${ }^{+}$T-cell memory. Immunol. Rev. 211, 67-80 (2006).

54. Haring, J. S., Badovinac, V. P., Olson, M. R., Varga, S. M \& Harty, J. T. In vivo generation of pathogen-specific Th1 cells in the absence of the IFN- $\gamma$ receptor J. Immunol. 175, 3117-3122 (2005).

55. Kronenberg, M. Toward an understanding of NKT cell biology: progress and paradoxes. Annu. Rev. Immunol. 23, 877-900 (2005)

56. Taniguchi, M., Seino, K. \& Nakayama, T. The NKT cell system: bridging innate and acquired immunity. Nature Immunol. 4, 1164-1165 (2003).

57. Taieb, J. et al. A novel dendritic cell subset involved in tumor immunosurveillance. Nature Med. 12, 214-219 (2006)

58. Lee, S. J. et al. Interferon regulatory factor- 1 is prerequisite to the constitutive expression and IFN- $\gamma$-induced upregulation of B7-H1 (CD274). FEBS Lett. 580, 755-762 (2006).

59. Vitale, M. et al. NK-dependent DC maturation is mediated by TNF $\alpha$ and IFN $\gamma$ released upon engagement of the NKp30 triggering receptor Blood 106, 566-571 (2005).

60. Wilson, J. A., Bray, M., Bakken, R. \& Hart, M. K Vaccine potential of Ebola virus VP24, VP30, VP35 and VP40 proteins. Virology 286, 384-390 (2001).

61. Wilson, J. A. \& Hart, M. K. Protection from Ebola virus mediated by cytotoxic T lymphocytes specific for the viral nucleoprotein. J. Virol. 75, 2660-2664 (2001).

62. Pushko, P. et al. Recombinant RNA replicons derived from attenuated Venezuelan equine encephalitis virus protect guinea pigs and mice from Ebola hemorrhagic fever virus. Vaccine 19, 142-153 (2000).

63. $\mathrm{Xu}$, L. et al. Immunization for Ebola virus infection. Nature Med. 4, 37-42 (1998)

64. Jones, S. M. et al. Live attenuated recombinant vaccine protects nonhuman primates against Ebola and Marburg viruses. Nature Med. 11, 786-790 (2005).

65. Sullivan, N. J. et al. Immune protection of nonhuman primates against Ebola virus with single low-dose adenovirus vectors encoding modified GPs. PLoS Med. 3, e177 (2006)

66. Bray, M. \& Paragas, J. Experimental therapy of filovirus infections. Antiviral Res. 54, 1-17 (2002).

67. Geisbert, T. W. et al. Evaluation in nonhuman primates of vaccines against Ebola virus. Emerg. Infect. Dis. 8, 503-507 (2002).

68. Ignatyev, G. M., Agafonov, A. P., Streltsova, M. A. \& Kashentseva, E. A. Inactivated Marburg virus elicits a nonprotective immune response in Rhesus monkeys. J. Biotechnol. 44, 111-118 (1996)

69. Hevey, M., Negley, D., Geisbert, J., Jahrling, P. \& Schmaljohn, A. Antigenicity and vaccine potential of Marburg virus glycoprotein expressed by baculovirus recombinants. Virology 239, 206-216 (1997).

70. Wilson, J. A. et al. Epitopes involved in antibodymediated protection from Ebola virus. Science 287, 1664-1666 (2000) This is the strongest of several demonstrations of antibody-mediated prevention of lethal filoviral disease in rodent models; here, monoclonal antibodies of differing specificities and in vitro functions are shown to protect in a mouse mode of Ebola virus. Evidence that filovirus-specific antibodies (either monoclonal or polyclonal) can prevent disease in non-human primates is still lacking (for example, reference 76).

71. Gupta, M., Mahanty, S., Bray, M., Ahmed, R. \& Rollin, P. E. Passive transfer of antibodies protects immunocompetent and imunodeficient mice against lethal Ebola virus infection without complete inhibition of viral replication. J. Virol. 75, 4649-4654 (2001).

72. Parren, P. W., Geisbert, T. W., Maruyama, T., Jahrling, P. B. \& Burton, D. R. Pre- and postexposure prophylaxis of Ebola virus infection in an animal model by passive transfer of a neutralizing human antibody. J. Virol. 76, 6408-6412 (2002). 
73. Martini, G. A. \& Siegert, R. Marburg virus disease (Springer-Verlag Berlin, New York, 1971). This is a classic monograph that contains chapters on the clinical presentation, treatment efforts and discovery of causative agent in the first recognized filovirus outbreak in Europe in 1967. Because subsequent Marburg virus outbreaks have occurred in African sites poorly served by advanced medical care, this remains the best description of Marburg-virus disease in humans, and is updated by one of the key 1967 scientists in reference 3 .

74. Mupapa, K. et al. Treatment of Ebola hemorrhagic fever with blood transfusions from convalescent patients. International Scientific and Technical Committee. J. Infect. Dis. 179 (Suppl. 1), 18-23 (1999).

75. Gupta, M. et al. Persistent infection with Ebola virus under conditions of partial immunity. J. Virol. 78, 958-967 (2004).

76. Oswald, W. B. et al. Neutralizing antibody fails to impact the course of Ebola virus infection in monkeys. PLoS Pathog. 3, e9 (2007)

77. Burnett, J. C., Henchal, E. A., Schmaljohn, A. L. \& Bavari, S. The evolving field of biodefence: therapeutic developments and diagnostics. Nature Rev. Drug Discov. 4, 281-297 (2005).

78. Sullivan, N. J., Sanchez, A., Rollin, P. E., Yang, Z. Y. \& Nabel, G. J. Development of a preventive vaccine for Ebola virus infection in primates. Nature 408, 605-609 (2000)

This reference provides the earliest demonstration of a genetic vaccine capable of preventing Ebolavirus disease in non-human primates. The authors' subsequent studies showed glycoprotein antigen expressed in replication-defective adenovirus to be key ingredient.

79. Riemenschneider, J et al Comparison of individual and combination DNA vaccines for $B$. anthracis, Ebola virus, Marburg virus and Venezuelan equine encephalitis virus. Vaccine 21, 4071-4080 (2003).

80 Bukreyev, A et al. A single intranasal inoculation with a paramyxovirus-vectored vaccine protects guinea pigs against a lethal-dose Ebola virus challenge. J. Virol. 80, 2267-2279 (2006).

81. Bukreyev, A. et al. Successful topical respiratory tract immunization of primates against Ebola virus. J. Virol. 81, 6378-6388 (2007)

82. Daddario-DiCaprio, K. M. et al. Postexposure protection against Marburg haemorrhagic fever with recombinant vesicular stomatitis virus vectors in non-human primates: an efficacy assessment. Lancet 367, 1399-1404 (2006).

83. Feldmann, H. et al. Effective post-exposure treatment of Ebola infection. PLoS Pathog. 3, e2 (2007).

84. Ebihara, $\mathrm{H}$. et al. Molecular determinants of Ebola virus virulence in mice. PLoS Pathog. 2 e 73 (2006).

85. Swanepoel, R. et al. Experimental inoculation of plants and animals with Ebola virus. Emerg. Infect. Dis. 2, 321-325 (1996)

86. Yao, S. \& Chen, L. Reviving exhausted T lymphocytes during chronic virus infection by B7-H1 blockade. Trends. Mol. Med. 12, 244-246 (2006).

87. Leroy, E. M. et al. Fruit bats as reservoirs of Ebola virus. Nature 438, 575-576 (2005).

88. Feldmann, H., Slenczka, W. \& Klenk, H. D. Emerging and reemerging of filoviruses. Arch. Virol. Suppl. 11, 77-100 (1996).
89. Towner, J. S. et al. Marburgvirus genomics and association with a large hemorrhagic fever outbreak in Angola. J. Virol. 80, 6497-6516 (2006)

90. Jahrling, P. B. et al. Experimental infection of cynomolgus macaques with Ebola-Reston filoviruses from the 1989-1990 U.S. epizootic. Arch. Virol. Suppl. 11, 115-134 (1996).

91. Bwaka, M. A. et al. Ebola hemorrhagic fever in Kikwit, Democratic Republic of the Congo: clinical observations in 103 patients. J. Infect. Dis. 179 (Suppl. 1), 1-7 (1999). This is a good overview, by an international team, of the clinical presentation of human Ebola-virus disease in a sizeable and deadly outbreak.

92. Geisbert, T. W. et al. Treatment of Ebola virus infection with a recombinant inhibitor of factor VIla/tissue factor: a study in rhesus monkeys. Lancet 362, 1953-1958 (2003).

93. Borio, L. et al. Hemorrhagic fever viruses as biological weapons: medical and public health management. JAMA 287, 2391-2405 (2002).

94. Hevey, M. et al. Marburg virus vaccines: comparing classical and new approaches. Vaccine 20, 586-593 (2001).

95. Chepurnov, A. A. et al. Attempts to develop a vaccine against Ebola fever. Vopr. Virusol. 40, 257-260 (1995) (in Russian).

96. Bray, M., Davis, K., Geisbert, T., Schmaljohn, C. \& Huggins, J. A mouse model for evaluation of prophylaxis and therapy of Ebola hemorrhagic fever. J. Infect. Dis. 178, 651-661. (1998). This paper describes derivation of a mouseadapted variant of ZEBOV and provides evidence of many similarities between mouse and primate disease. That several subsequent studies have demonstrated differences between mouse and monkey disease manifested in the greater difficulty in protecting monkeys with vaccines and therapies, the selected use of the mouse model has not been negated.

97. Volchkov, V. E. et al. Recovery of infectious Ebola virus from complementary DNA: RNA editing of the GP gene and viral cytotoxicity. Science 291, 1965-1969 (2001).

98. Mellquist-Riemenschneider, J. L. et al. Comparison of the protective efficacy of DNA and baculovirus-derived protein vaccines for Ebola virus in guinea pigs. Virus. Res. 92, 187-193 (2003).

99. Vanderzanden, L. et al. DNA vaccines expressing either the GP or NP genes of Ebola virus protect mice from lethal challenge. Virology 246, 134-144 (1998)

100. Kobinger, G. P. et al. Chimpanzee adenovirus vaccine protects against Zaire Ebola virus. Virology 346, 394-401 (2006).

101. Swenson, D. L. et al. Virus-like particles exhibit potential as a pan-filovirus vaccine for both Ebola and Marburg viral infections. Vaccine 23, 3033-3042 (2005)

102. Hevey, M., Negley, D. \& Schmaljohn, A Characterization of monoclonal antibodies to Marburg virus (strain Musoke) glycoprotein and identification of two protective epitopes. Virology 314, 350-357 (2003).
103. Takada, A et al. Identification of protective epitopes on Ebola virus glycoprotein at the single amino acid level by using recombinant vesicular stomatitis viruses. J. Virol. 77, 1069-1074 (2003).

104. Jeffers, S. A., Sanders, D. A. \& Sanchez, A. Covalent modifications of the Ebola virus glycoprotein. J. Virol. 76, 12463-12472 (2002)

105. Volchkov, V. E., Volchkova, V. A., Dolnik, O. Feldmann, H. \& Klenk, H. D. Polymorphism of filovirus glycoproteins. Adv. Virus Res. 64, 359-381 (2005).

106. Sanchez, A., Trappier, S. G., Mahy, B. W., Peters, C. J. $\&$ Nichol, S. T. The virion glycoproteins of Ebola viruses are encoded in two reading frames and are expressed through transcriptional editing. Proc. Natl Acad. Sci. USA 93, 3602-3607 (1996).

107. Manicassamy, B., Wang, J., Jiang, H. \& Rong, L. Comprehensive analysis of Ebola virus GP1 in viral entry. J. Virol. 79, 4793-4805 (2005).

108. Weissenhorn, W., Carfi, A., Lee, K. H., Skehel, J. J. \& Wiley, D. C. Crystal structure of the Ebola virus membrane fusion subunit, GP2, from the envelope glycoprotein ectodomain. Mol. Cell 2, 605-616 (1998).

109. Kuhn, J. H. et al. Conserved receptor-binding domains of Lake Victoria marburgvirus and Zaire ebolavirus bind a common receptor. J. Biol. Chem. 281, 15951-15958 (2006)

110. Yang, Z. Y. et al. Identification of the Ebola virus glycoprotein as the main viral determinant of vascular cell cytotoxicity and injury. Nature Med. 6, 886-889 (2000).

111. Simmons, G., Wool-Lewis, R. J., Baribaud, F., Netter, R. C. \& Bates, P. Ebola virus glycoproteins induce global surface protein down-modulation and loss of cell adherence. J. Virol. 76, 2518-2528 (2002).

112. Bukreyev, A., Volchkov, V. E., Blinov, V. M. \& Netesov, S. V. The GP-protein of Marburg virus contains the region similar to the 'immunosuppressive domain' of oncogenic retrovirus P15E proteins. FEBS Lett. 323, 183-187 (1993).

\section{Acknowledgements}

The views, opinions and/or findings contained in this report are those of the authors and should not be construed as an official Department of the Army or Johns Hopkins University position, policy, or decision unless designated by other documentation. This work was supported in part by the Defense Threat Reduction Agency.

Competing interests statement

The authors declare no competing financial interests.

\section{DATABASES}

The following terms in this article are linked online to: Entrez Gene: http://www.ncbi.nlm.nih.gov/entrez/query. fcgi?db=gene

B7-H1 |CD40 | CD86 | DC-SIGN | ICAM3 | IFN $\alpha$ | IFN $\beta$ | IFN $\gamma$ | IL-12 | L-SIGN

Entrez Genome: http://www.ncbi.nlm.nih.gov/sites/

entrez?Db=genome

MARV ISEBOV IZEBOV

Access to this links box is available online. 